\title{
Article \\ Dielectrophoresis-Based Positioning of Carbon Nanotubes for Wafer-Scale Fabrication of Carbon Nanotube Devices
}

\author{
Joevonte Kimbrough ${ }^{1}$, Lauren Williams ${ }^{1}$, Qunying Yuan ${ }^{2} \mathbb{D}$ and Zhigang Xiao ${ }^{1, *}$ \\ 1 Department of Electrical Engineering and Computer Science, Alabama A\&M University, \\ Normal, AL 35762, USA; jkimbro3@bulldogs.aamu.edu (J.K.); lwilli81@bulldogs.aamu.edu (L.W.) \\ 2 Department of Biological and Environmental Science, Alabama A\&M University, Normal, AL 35762, USA; \\ qunying.yuan@aamu.edu \\ * Correspondence: zhigang.xiao@aamu.edu; Tel.: +1-256-372-5679; Fax: +1-256-372-5855
}

Citation: Kimbrough, J.; Williams, L.; Yuan, Q.; Xiao, Z. DielectrophoresisBased Positioning of Carbon Nanotubes for Wafer-Scale Fabrication of Carbon Nanotube Devices. Micromachines 2021, 12, 12. https://dx.doi.org/10.3390/mi 12010012

Received: 4 December 2020 Accepted: 23 December 2020 Published: 25 December 2020

Publisher's Note: MDPI stays neutral with regard to jurisdictional claims in published maps and institutional affiliations.

Copyright: () 2020 by the authors. Licensee MDPI, Basel, Switzerland. This article is an open access article distributed under the terms and conditions of the Creative Commons Attribution (CC BY) license (https: / / creativecommons.org/ licenses/by/4.0/).

\begin{abstract}
In this paper, we report the wafer-scale fabrication of carbon nanotube field-effect transistors (CNTFETs) with the dielectrophoresis (DEP) method. Semiconducting carbon nanotubes (CNTs) were positioned as the active channel material in the fabrication of carbon nanotube field-effect transistors (CNTFETs) with dielectrophoresis (DEP). The drain-source current $\left(\mathrm{I}_{\mathrm{DS}}\right)$ was measured as a function of the drain-source voltage $\left(\mathrm{V}_{\mathrm{DS}}\right)$ and gate-source voltage $\left(\mathrm{V}_{\mathrm{GS}}\right)$ from each CNTFET on the fabricated wafer. The $\mathrm{I}_{\mathrm{DS}}$ on/off ratio was derived for each CNTFET. It was found that $87 \%$ of the fabricated CNTFETs was functional, and that among the functional CNTFETs, $30 \%$ of the CNTFETs had an $\mathrm{I}_{\mathrm{DS}}$ on/off ratio larger than 20 while $70 \%$ of the CNTFETs had an $\mathrm{I}_{\mathrm{DS}}$ on/off ratio lower than 20. The highest $I_{D S}$ on/off ratio was about 490 . The DEP-based positioning of carbon nanotubes is simple and effective, and the DEP-based device fabrication steps are compatible with Si technology processes and could lead to the wafer-scale fabrication of CNT electronic devices.
\end{abstract}

Keywords: dielectrophoresis (DEP); semiconducting carbon nanotubes; carbon nanotube field-effect transistors (CNTFETs)

\section{Introduction}

Carbon nanotube-based electronic devices such as carbon nanotube field-effect transistors (CNTFETs) and electronic circuits have been investigated extensively in the past years for the application of future nanoelectronic devices [1-15]. Since carbon nanotubes (CNTs) have a high aspect (ratio of the length to diameter) with a diameter of several nanometers and a length of several micrometers, the electrons or holes in the tubes are subject to a strong quantum-confinement effect in all directions perpendicular to the tube, making their transport in the tube a ballistic transport with less scattering and collisions [16,17]. These properties are not available in bulk electronic materials and can make carbon nanotube field-effect transistors (CNTFETs) operate at a high speed and low power without energy dissipating in the tube [18].

The wafer-scale fabrication of carbon nanotube electronic circuits can lead to the production and application of carbon nanotube electronic devices and has recently been reported by researchers [19-21]. In this paper, we report the wafer-scale fabrication of carbon nanotube field-effect transistors (CNTFETs) using dielectrophoresis (DEP), which is simple and unique compared to other methods [22,23]. Carbon nanotubes were positioned and assembled as the active channel material in the wafer-scale fabrication of carbon nanotube field-effect transistors (CNTFETs) using electric field-directed dielectrophoresis (DEP). Dielectrophoresis (DEP) is a translational motion of neutral matter caused by the polarization effects in a nonuniform electric field and has recently been investigated theoretically and experimentally for the deposition and alignment of CNTs [24-29]. It is also effective in assembling other materials such as liquid metal [30]. Aligned and dense carbon nanotubes (CNTs) can be obtained in the DEP process by optimizing the ac frequency, the 
trapping time, and the CNT solution concentration [31-33]. Impurities such as the metal impurity in CNTs, which come from the growth of CNTs due to the metal catalyst, could electrically short CNTFETs and cannot be tolerated in the fabrication of CNTFETs [34,35]. However, the impurities can be filtered in the pre-DEP process with solvents such as Nmethyl pyrrolidone (NMP), making the DEP-based fabrication of CNTFETs appealing for obtaining high-performance carbon nanotube field-effect transistors and electronic devices. Since the DEP-based device fabrication steps are compatible with Si technology processes, they are capable of being further optimized by following process development protocols practiced by the semiconductor industry and can lead to the wafer-scale fabrication of CNT electronic devices and sensors.

\section{Experimental Details}

\subsection{CNT-NMP Solution Preparation}

Carbon nanotube (CNT) powder with $98 \%$ semiconducting CNTs (from the NanoIntergris Company) was used in this research. The CNT powder was dispersed ultrasonically in the Nmethyl-2-pyrrolidone (NMP) solution (from the Sigma-Aldrich Company) for the dielectrophoresis (DEP) process. The CNTs were subjected to a cleaning process for filtering any possible impurity in the CNTs before being used for the DEP process. $1 \mathrm{mg}$ CNT powder was added to $20 \mathrm{ml} \mathrm{NMP}$ and sonicated for $10 \mathrm{~min}$. The CNT solution was then centrifuged at 14,000 rpm for $30 \mathrm{~min}$. The resultant supernatant was decanted for the sedimented carbon nanotubes, which were again subjected to the cleaning cycle with a fresh NMP. The cleaning process was repeated three times. Finally, the sedimented carbon nanotubes were added into a $30 \mathrm{ml}$ NMP solution; the solution was sonicated for $5 \mathrm{~min}$. After the sonication, the carbon nanotubes were separated and uniformly dispersed in the NMP solution, and the CNT-NMP solution was ready for the dielectrophoresis process in the following device fabrication.

\subsection{FET Device Fabrication}

A 3-inch diameter $350-\mu \mathrm{m}$ thick n-type $<100>$ silicon (Si) wafer (from Virginia Semiconductor, Inc.) was used as the substrate in this research. The $\mathrm{Si}$ wafer was about $350 \mu \mathrm{m}$ thick and had a resistivity of about $3 \Omega \mathrm{cm}$. The wafer was initially oxidized at $1100{ }^{\circ} \mathrm{C}$ for 120 min to grow a silicon dioxide $\left(\mathrm{SiO}_{2}\right)$ layer of about $1 \mu \mathrm{m}$ thickness using wet oxidation. A PVD 75 (Kurt J. Lesker Company, Pittsburgh, PA, USA) e-beam/thermal evaporation system was used to grow chromium $(\mathrm{Cr}) /$ gold $(\mathrm{Au})$ thin films for the fabrication of $\mathrm{Cr} / \mathrm{Au}$ electrodes and device metallization. The process chamber had a background pressure of $2 \times 10^{-7}$ Torr, and the film thickness was controlled by an INFICON deposition monitor. An ALD-150LX system (Kurt J. Lesker Company, Pittsburgh, USA) was used to grow the hafnium dioxide $\left(\mathrm{HfO}_{2}\right)$ thin film as the gate oxide in the fabrication of CNTFETs [36,37]. A set of four-piece photo masks was designed and used for the fabrication of the carbon nanotube field-effect transistors (CNTFETs). The photo masks were fabricated by Photoscience, Inc. Figure $1 \mathrm{a}-\mathrm{c}$ show the fabrication steps of CNTFETs. The first mask was used to define and pattern 5-nm thick $\mathrm{Cr} / 100-\mathrm{nm}$ thick $\mathrm{Au}$ (99.99\% pure from Alfa Aesar) source and drain electrodes with gaps of about $3 \mu \mathrm{m}$ using standard ultraviolet (UV) photolithography and metal lift-off processes (Figure 1a). The thin Cr layer was used to enhance the adhesion of $\mathrm{Au}$ to the underlayer. The device wafer was designed to have 30 CNTFETs on it. After the first mask, 30 pairs of electrodes were fabricated on the wafer (Figure 2), and all the electrodes were connected in parallel to two major pads, which were applied with the ac voltages during the subsequent DEP process. 


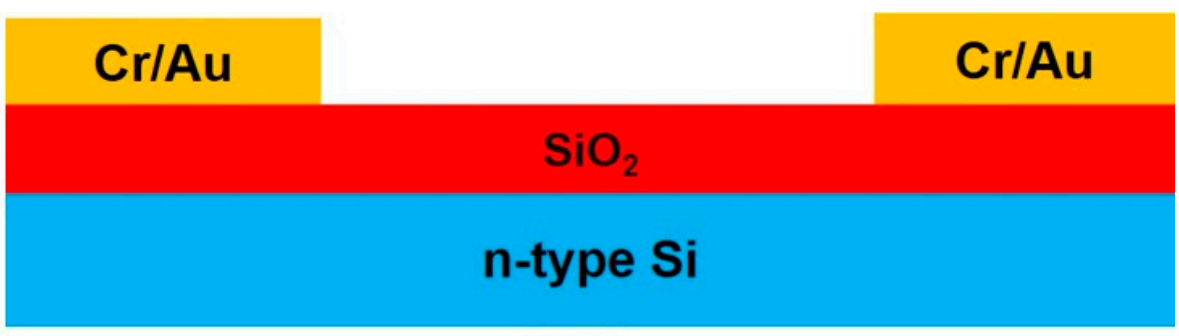

\section{(a)}

AC Voltage Source

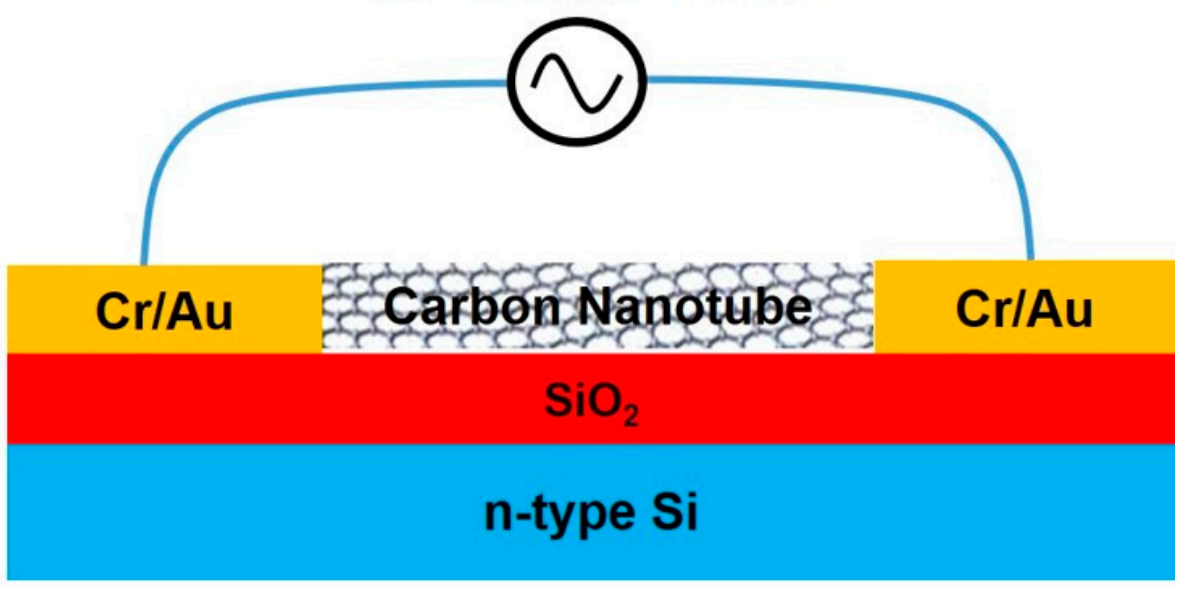

(b)

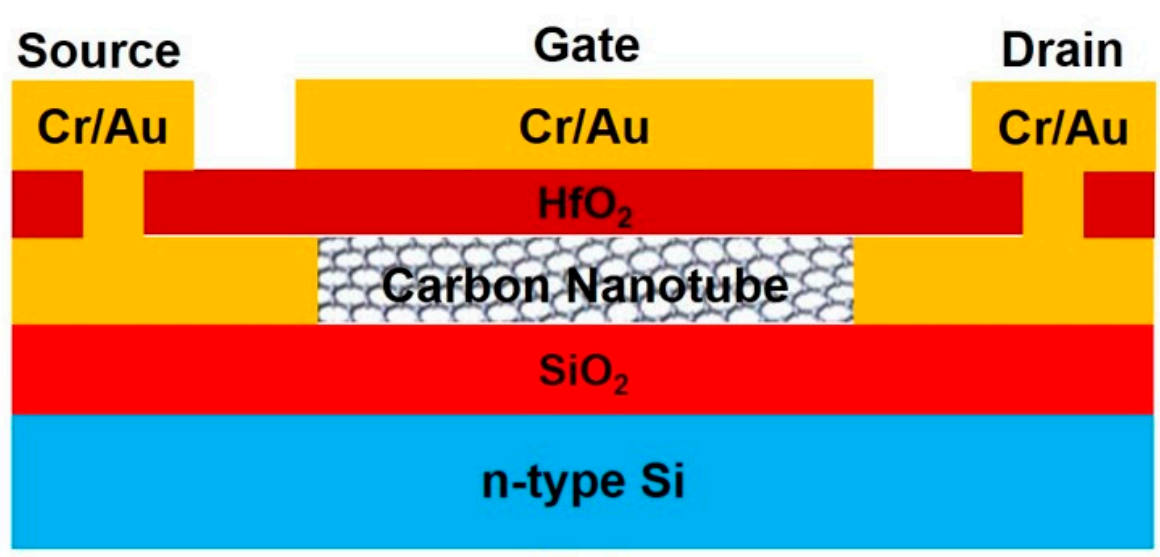

(c)

Figure 1. Carbon nanotube field-effect transistor (CNTFET) device fabrication steps. (a) $\mathrm{Cr} / \mathrm{Au}$ electrode definition. (b) Alignment and assembling of CNTs with the DEP process under an applied sinusoidal voltage source between source and drain electrodes; the subsequent steps of the etching of $\mathrm{Cr} / \mathrm{Au}$ films and the definition of $\mathrm{HfO}_{2}$ gate oxide are not depicted in this figure. (c) Source, drain, and gate metal electrode definitions. 


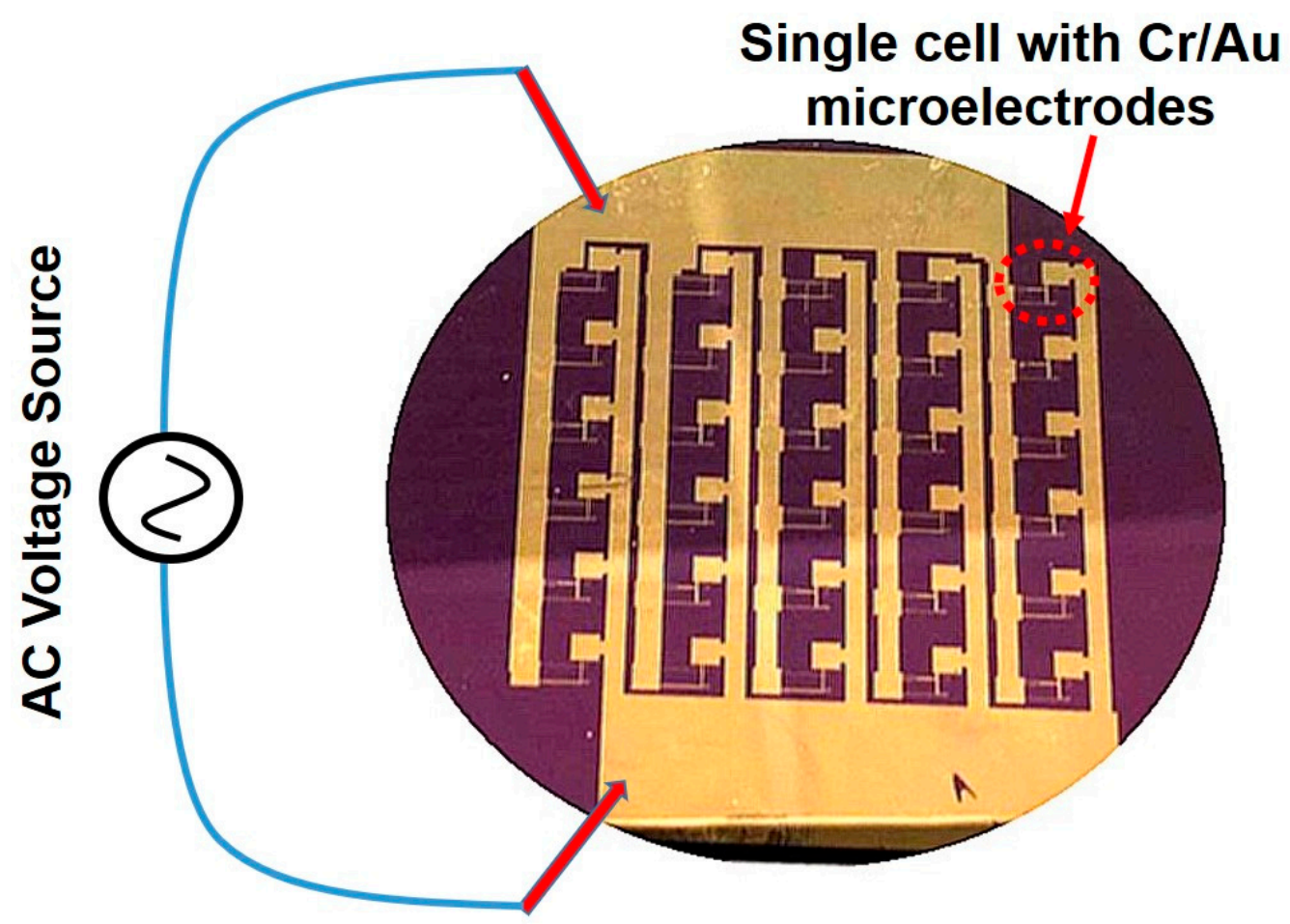

Figure 2. The wafer with 30 pairs of $\mathrm{Cr} / \mathrm{Au}$ electrodes fabricated on it, where all the electrodes were connected in parallel to two major pads to which the ac voltages were applied during the subsequent DEP process.

After the fabrication of the $\mathrm{Cr} / \mathrm{Au}$ electrodes on the wafer, the dielectrophoresis (DEP) process was then performed to deposit and align CNTs across the gap of electrodes (Figure 1b). A sinusoidal voltage source was connected to the two major pads of the wafer (Figure 2), and the wafer was then dipped into a glass beaker filled with the CNT-NMP solution prepared as described above. A sinusoidal voltage with a peak-to-peak voltage of $10 \mathrm{~V}$ and frequency of $1 \mathrm{MHz}$ was applied to the electrodes for $10 \mathrm{~min}$. After that, the wafer was taken out from the beaker. The solvent was blown off the wafer surface with nitrogen gas. The wafer surface was then cleaned with 2-Propanol and rinsed in deionized (DI) water for $1 \mathrm{~min}$. After that, the wafer was dried with nitrogen gas. The CNTs were imaged in a JEOL JSM-6610LV scanning electron microscope (JEOL Ltd, Akishima, Japan). Figure 3a shows the scanning electron micrograph (SEM) image of CNTs positioned between a pair of electrodes in a CNT-NMP solution with a higher concentration of CNTs using the DEP process, while Figure $3 b$ is the enlarged view of the CNTs across the gap of electrodes, showing a network-like profile of CNTs. Figure $4 \mathrm{a}, \mathrm{b}$ show the SEM images of CNTs positioned between the electrodes in a CNT-NMP solution with a lower concentration of CNTs using the DEP process for two pairs of electrodes. As shown in Figure $4 \mathrm{a}, \mathrm{b}$, although they were positioned with the same DEP process conditions, the CNTs in Figure $4 \mathrm{a}, \mathrm{b}$ had varying profiles because of the random and uncontrollable property of CNTs dispersed in the CNT-NMP solution. Figure 4 also shows that the positioned CNTs are not single-tube and are bundling tubes (a single tube should have a diameter of several nanometers). The CNT-NMP solution with a lower concentration of CNTs was used for the final device fabrication. 

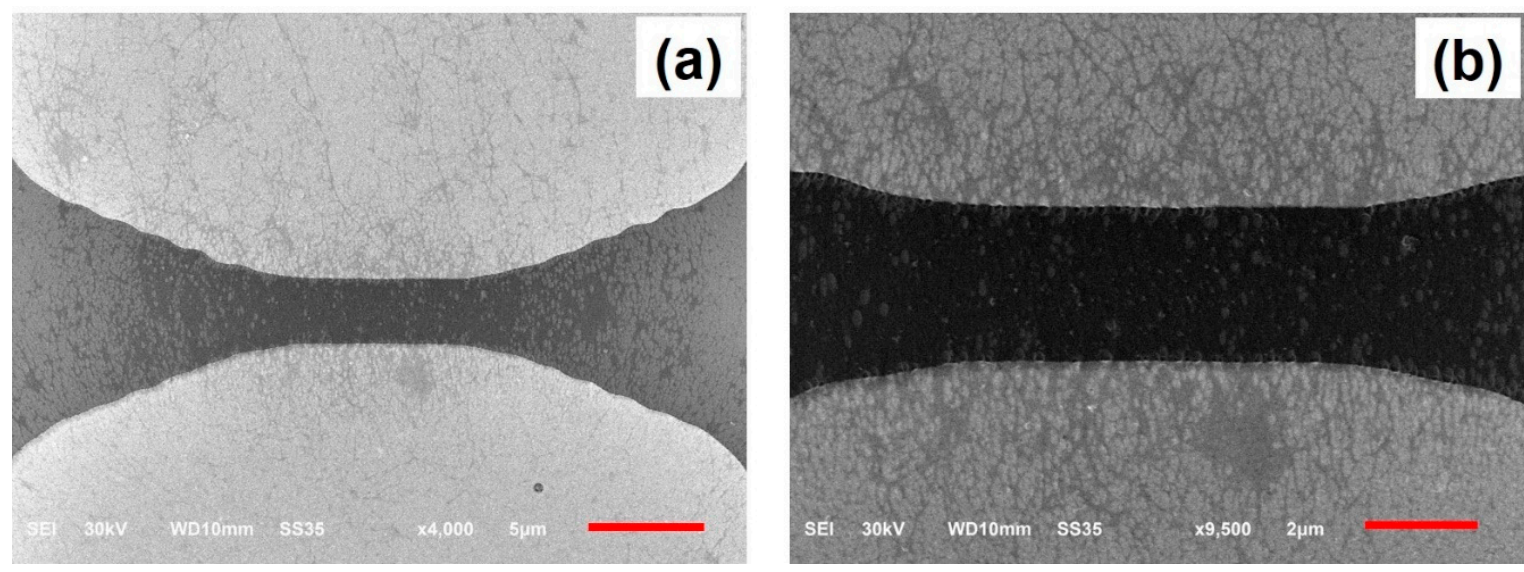

Figure 3. (a) SEM image of CNTs aligned and assembled between a pair of electrodes in a CNT-NMP solution with a higher concentration of CNTs using the DEP process; (b) enlarged view of the CNTs, showing a network-like profile of CNTs. The scale bar is $5 \mu \mathrm{m}$.
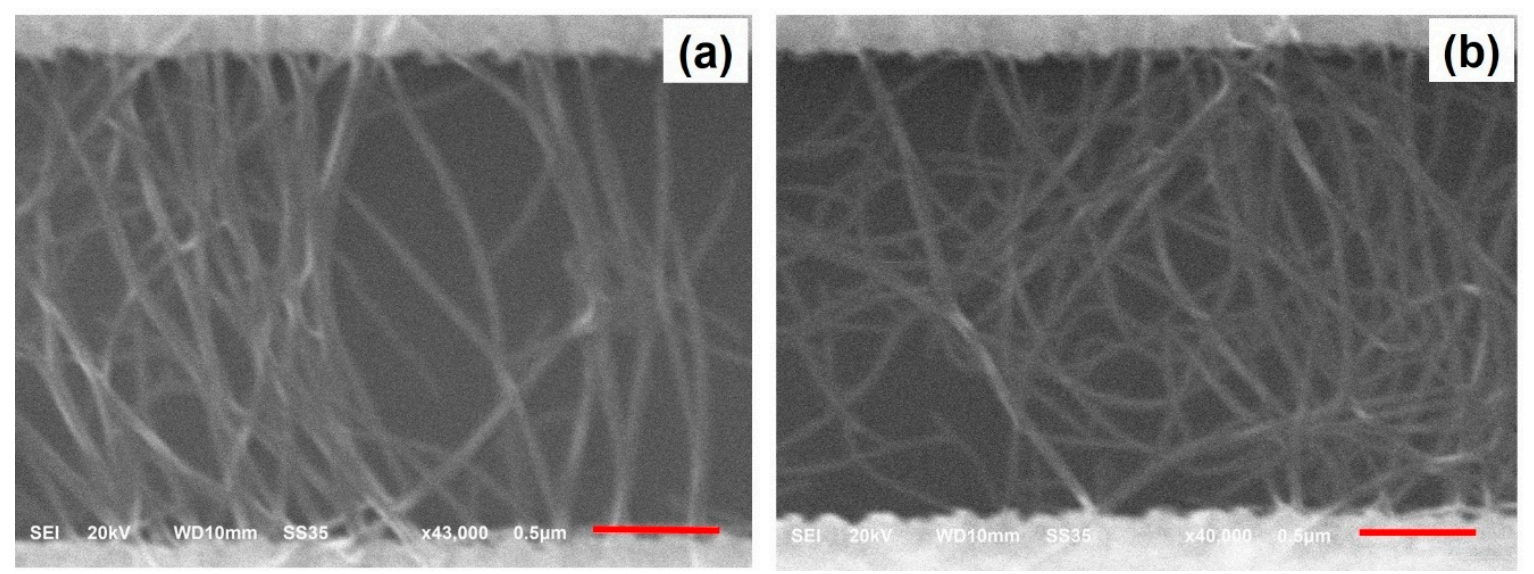

Figure 4. SEM images of CNTs aligned and assembled between the electrodes in two pairs of electrodes in a CNT-NMP solution with a lower concentration of CNTs using the DEP process, where both (a) and (b) show profiles of CNTs with some alignment of CNTs across the electrodes. The scale bar is $0.5 \mu \mathrm{m}$.

The second mask was applied to create patterns for etching the $\mathrm{Cr} / \mathrm{Au}$ metal film that connected with the pairs of electrodes using the UV lithography and to separate the electrodes into individual pairs of electrodes. After the UV lithography process, each pair of electrodes, together with the CNTs between the gap, was covered by Shipley 1818 positive photoresist, but all other areas on the wafer were open without being covered by the photoresist. The wafer was dipped in a gold etchant (Transene, Danvers, MA, USA) for $30 \mathrm{~s}$, then in DI water for $1 \mathrm{~min}$, and in a chromium etchant (Transene, Danvers, MA, USA) for $30 \mathrm{~s}$ to remove all the $\mathrm{Cr} / \mathrm{Au}$ except that protected by the photoresist. The wafer was finally rinsed in DI water for $1 \mathrm{~min}$ and was dried with nitrogen gas. After that, a 10-nm thick $\mathrm{HfO}_{2}$ film was deposited over the whole wafer as the gate oxide using plasma-enhanced atomic layer deposition.

The third mask was applied to open a window through the $\mathrm{HfO}_{2}$ film on the source/ drain for the final source/drain metal contact using the UV lithography. After the UV lithography process, the wafer was covered by Shipley 1818 photoresist, except for a $30 \mu \mathrm{m} \times 30 \mu \mathrm{m}$ small area on the source/drain. The wafer was then dipped in buffered oxide etchant (BOE) (Transene, Danvers, MA, USA) for 3 min to etch the $\mathrm{HfO}_{2}$ through the patterned windows on the source/drain for the contact.

Finally, the fourth photoresist mask aligned to the opened windows was applied to define the source, drain, and gate metal contacts (100-nm thick $\mathrm{Au} / 5-\mathrm{nm}$ thick $\mathrm{Cr}$ ) via 
e-beam evaporation and metal lift-off. Again, $\mathrm{Cr}$ was used to enhance the adhesion of $\mathrm{Au}$ to the underneath layer $\left(\mathrm{HfO}_{2}\right)$. Figure $1 \mathrm{c}$ shows the cross-sectional diagram of the CNTFET device, and Figure 5 shows the scanning electron micrograph of the top view of the fabricated CNTFET.

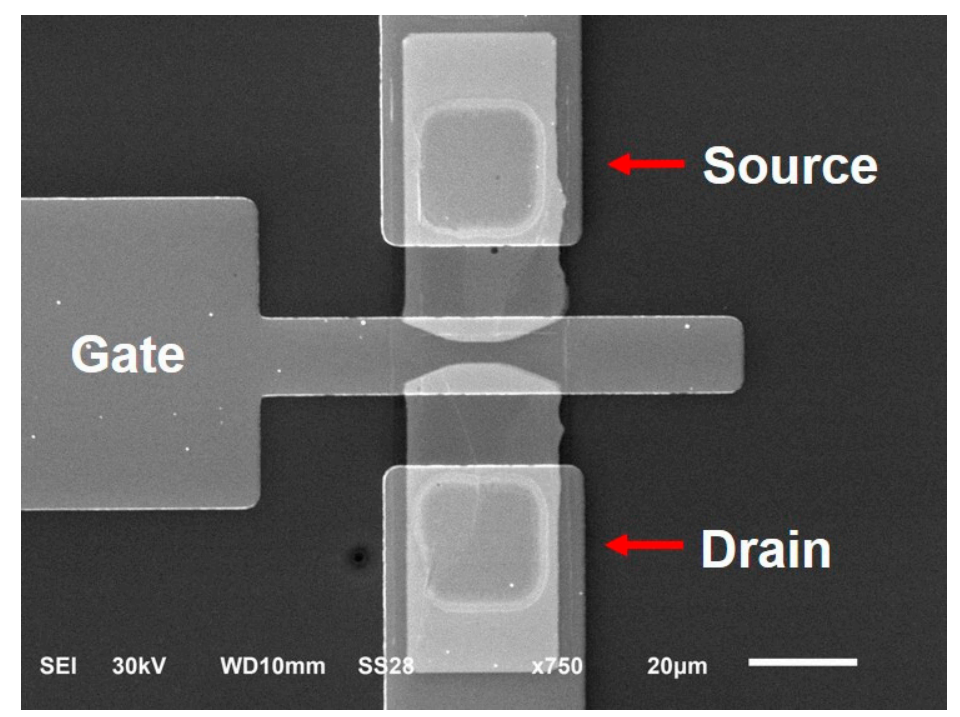

Figure 5. SEM image of a fabricated CNTFET.

\subsection{Electrical Measurements}

Electrical contacts to the substrate, source, drain and gate electrodes were performed at room temperature using a probe station (CM-170 from Signatone, Gilroy, USA) equipped with four triax micromanipulated probes. The wafer substrate remained electrically unconnected (floating) during the measurements. Electrical signals for the device characterization were sourced and measured using a precision semiconductor parameter analyzer (4156C from Agilent, Santa Clara, CA, USA).

\subsection{Electrical Breakdown Process}

To increase the IDS on/off ratios with the electrical breakdown method [38,39], CNTFETs were fabricated using the same processes. The IV curves and transfer characteristics of the CNTFETs were first measured as fabricated; after that, the devices were subjected to an electrical breakdown process, which consisted of sweeping $V_{D S}$ from $-8 \mathrm{~V}$ to $8 \mathrm{~V}$ at different $V_{G S}$ values that varied from $-8 \mathrm{~V}$ to $8 \mathrm{~V}$ in steps of $0.5 \mathrm{~V}$ until the $\mathrm{I}_{\mathrm{DS}}$ values decreased to values that were about five to 10 times smaller. Then, the IV curves and transfer characteristics of the CNTFETs were measured again.

\section{Results and Discussion}

After completion of the device fabrication, each carbon nanotube field-effect transistor (CNTFET) fabricated on the wafer was probed and measured one by one as described above. It was found that $26(87 \%)$ of the 30 CNTFETs on the wafer were functional, while the other four were broken. Among the 26 functional CNTFETs, $30 \%$ of the CNTFETs had a drain-source current (IDS) on/ off ratio larger than 20 while $70 \%$ of the CNTFETs had a drain-source current $\left(I_{D S}\right)$ on/off ratio under 20. The highest drain-source current $\left(I_{D S}\right)$ on/off ratio was about 490 . The reason why the electrical properties such as the $\mathrm{I}_{\mathrm{DS}}$ on/off ratio varied in the CNTFETs was because the profile and number of CNTs positioned between the electrodes varied in the CNTFETs, as shown in Figure 4a,b. Both the profile and number of aligned CNTs can have effects on the electrical property of CNTFETs. The CNTFET with more CNTs had a lower channel resistance and therefore a higher $\mathrm{I}_{\mathrm{DS}}$ value. The carbon nanotubes used in this research had about $98 \%$ semiconducting carbon tubes and about $2 \%$ metallic carbon tubes. The metallic tubes in the CNTs could be the major 
factor responsible for the variation of the $\mathrm{I}_{\mathrm{DS}}$ on/off ratio in the CNTFETs. The metallic carbon nanotube has a zero band gap and functions like metal, and the resistance cannot be modulated with the applied gate voltage to CNTFETs. The semiconducting carbon nanotube contributes to the increase of the $\mathrm{I}_{\mathrm{DS}}$ on/off ratio in a CNTFET, while the metallic carbon nanotube functions in an opposite way $[40,41]$. A higher number of metallic CNTs in the channel of CNTFET makes the modulation of channel resistance more difficult, resulting in a lower $\mathrm{I}_{\mathrm{DS}}$ on/off ratio. Since the metallic carbon nanotubes could not be filtered in the DEP process, they were randomly assembled into the channel of CNTFET, resulting in the variation of the $\mathrm{I}_{\mathrm{DS}}$ on/off ratio in CNTFETs.

Figure 6a-f show the drain-source current $\left(\mathrm{I}_{\mathrm{DS}}\right)$ versus the drain-source voltage $\left(\mathrm{V}_{\mathrm{DS}}\right)$ at various $V_{G S}$ values (Figure $6 \mathrm{a}, \mathrm{c}, \mathrm{e}$ ) and the $\mathrm{I}_{\mathrm{DS}}-\mathrm{V}_{\mathrm{GS}}$ transfer curves of the CNTFET at various $V_{D S}$ values (Figure $\left.6 b, d, f\right)$ for three functional devices, respectively. The $I_{D S}$ on/off ratio, defined as the maximum $I_{D S}$ value divided by the lowest one in the $I_{D S}-V_{G S}$ transfer curve, is 8 for the device in Figure 6b, 27 for the device in Figure 6d, and 10 for the device in Figure $6 \mathrm{f}$. All the devices present electrical properties of a p-channel field-effect transistor (FET), which are like those of the p-type carbon nanotube transistors reported by other researchers [42,43]. The $\mathrm{I}_{\mathrm{DS}}$ is sensitive to the $\mathrm{V}_{\mathrm{GS}}$ and can be modulated by $\mathrm{V}_{\mathrm{GS}}$, as shown in the figure. When increasing $\mathrm{V}_{\mathrm{GS}}$ negatively, the $\mathrm{I}_{\mathrm{DS}}$ values increase correspondingly. P-type transistors conduct holes when a negative voltage is applied to the gate. They do not conduct electrons, even at high positive gate voltages. The physical explanation for this is that the Fermi level at the contact metal-nanotube junction is closer to the valence band of the nanotube, leading to hole conduction and p-type behavior. The holes see a small barrier and can thus tunnel through, whereas the electrons see a much larger barrier and are not able to tunnel [44].

Figure 7a shows the drain-source current $\left(\mathrm{I}_{\mathrm{DS}}\right)$ versus the drain-source voltage $\left(\mathrm{V}_{\mathrm{DS}}\right)$ at various $\mathrm{V}_{\mathrm{GS}}$ values for the functional CNTFET that had the highest $\mathrm{I}_{\mathrm{DS}}$ on/off ratio among all the functional devices on the fabricated wafer, and it presents better IV curves, with the saturation like that of a silicon-based p-channel field-effect transistor [45]. Figure $7 \mathrm{~b}$ shows the $\mathrm{I}_{\mathrm{DS}}-\mathrm{V}_{\mathrm{GS}}$ transfer curves of the CNTFET at $\mathrm{V}_{\mathrm{DS}}=4 \mathrm{~V}, 3 \mathrm{~V}$, and $2 \mathrm{~V}$. The $\mathrm{I}_{\mathrm{DS}}$ on/off ratio is 61 at $\mathrm{V}_{\mathrm{DS}}=4 \mathrm{~V}, 190$ at $\mathrm{V}_{\mathrm{DS}}=3 \mathrm{~V}$, and 490 at $\mathrm{V}_{\mathrm{DS}}=2 \mathrm{~V}$. As described above, the reason why the CNTFET had a higher $\mathrm{I}_{\mathrm{DS}}$ on/off ratio is possibly because less or no metallic tubes were assembled in the channel during the DEP process. The $I_{D S}-V_{D S}$ curves in Figure $7 a$ are comparable with those reported by other researchers [46,47].

Figure 8a-d shows the comparison of the electrical characteristics of a fabricated CNTFET, which were measured as fabricated or after being subjected to the electrical breakdown process. Figure $8 \mathrm{a}, \mathrm{b}$ shows the electrical characteristics of the CNTFET, which were measured as fabricated. Figure 8a shows the drain-source current $\left(\mathrm{I}_{\mathrm{DS}}\right)$ versus drain-source voltage $\left(\mathrm{V}_{\mathrm{DS}}\right)$ and gate voltage $\left(\mathrm{V}_{\mathrm{GS}}\right)$, while Figure $8 \mathrm{~b}$ shows the transfer characteristics at $V_{D S}=5 \mathrm{~V}$ and $0.5 \mathrm{~V}$, where the $\mathrm{I}_{\mathrm{DS}}$ on/off ratio is 4 at $\mathrm{V}_{\mathrm{DS}}=5 \mathrm{~V}$ and 6 at $\mathrm{V}_{\mathrm{DS}}=0.5 \mathrm{~V}$. Figure $8 \mathrm{c}$, d shows the electrical characteristics of the CNTFET, which were measured after the CNTFET was subjected to the electrical breakdown process described in Section 2.4, where the $I_{D S}$ on/off ratio is about 339 at $V_{D S}=5 \mathrm{~V}$ and 488 at $V_{D S}=0.5 \mathrm{~V}$. Although it decreased the $I_{D}$ values, the electrical breakdown process significantly increased the $I_{D S}$ on/off ratios. This post-device fabrication process has been used to increase the IDS on/off ratio of CNTFETs and decrease the leakage current [38,39]. In the CNTFET channel with the intermixed presence of metallic and semiconducting CNTs, the electrical breakdown process can selectively destroy, by Joule heating, the metallic CNTs responsible for the unwanted electrical characteristics while preserving semiconducting CNTs. 


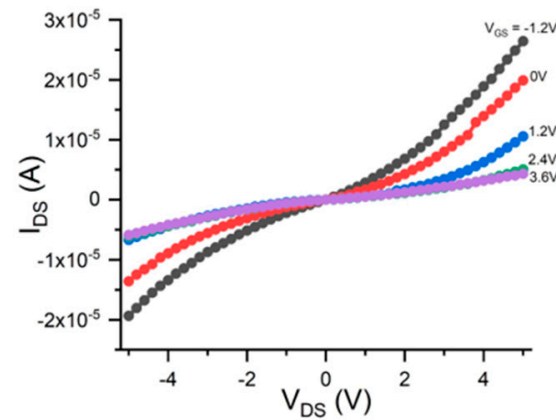

(a)

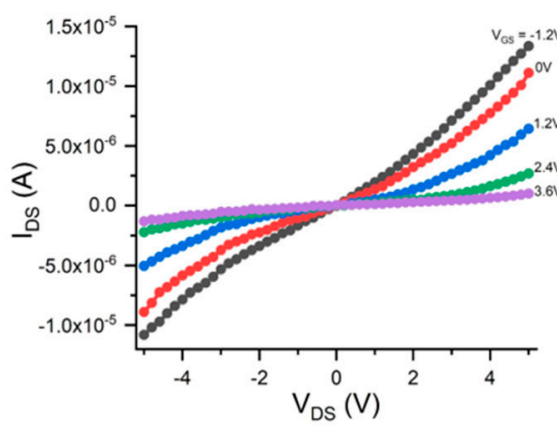

(c)



(e)

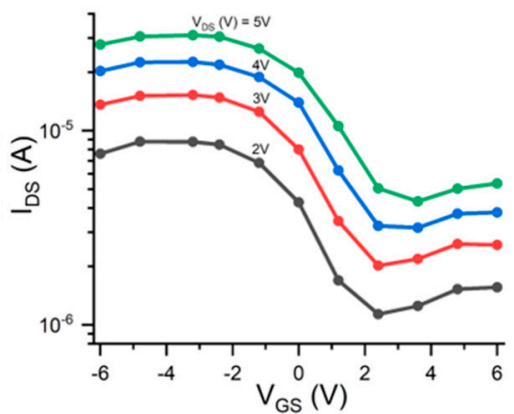

(b)



(d)



(f)

Figure 6. Electrical measurement results for three functional CNTFET devices: (a) Drain-source current $\left(\mathrm{I}_{\mathrm{DS}}\right)$ versus drain-source voltage $\left(\mathrm{V}_{\mathrm{DS}}\right)$ and gate voltage $\left(\mathrm{V}_{\mathrm{GS}}\right)$ and $(\mathbf{b})$ transfer characteristics at $\mathrm{V}_{\mathrm{DS}}=+5 \mathrm{~V},+4 \mathrm{~V},+3 \mathrm{~V}$, and $+2 \mathrm{~V}$ for device one, where the $\mathrm{I}_{\mathrm{DS}}$ on/off ratio is 8; (c) Drain-source current $\left(\mathrm{I}_{\mathrm{DS}}\right)$ versus drain-source voltage $\left(\mathrm{V}_{\mathrm{DS}}\right)$ and gate voltage $\left(\mathrm{V}_{\mathrm{GS}}\right)$ and $(\mathbf{d})$ transfer characteristics for device two, where the $\mathrm{I}_{\mathrm{DS}}$ on/off ratio is 27; (e) Drain-source current ( $\mathrm{I}_{\mathrm{DS}}$ ) versus drain-source voltage $\left(\mathrm{V}_{\mathrm{DS}}\right)$ and gate voltage $\left(\mathrm{V}_{\mathrm{GS}}\right)$ and $(\mathbf{f})$ transfer characteristics for device three, where the $\mathrm{I}_{\mathrm{DS}}$ on/off ratio is 10 . 


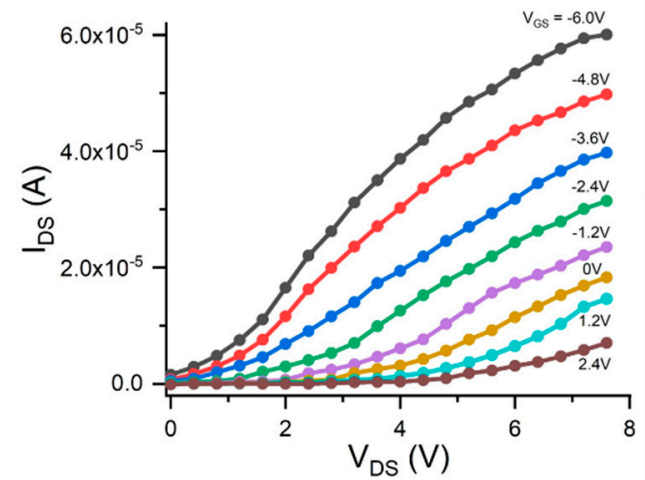

(a)

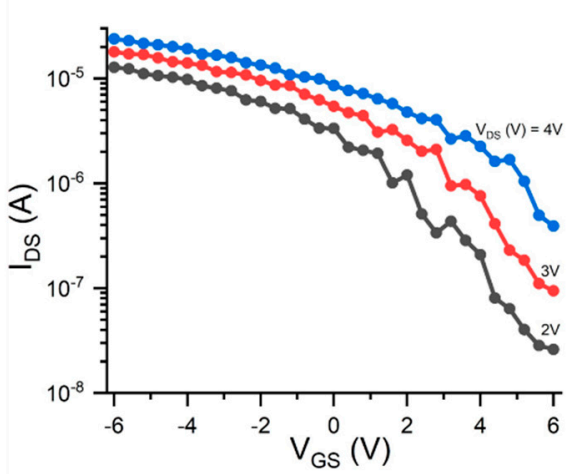

(b)

Figure 7. (a) Drain-source current ( $\left.\mathrm{I}_{\mathrm{DS}}\right)$ versus drain-source voltage $\left(\mathrm{V}_{\mathrm{DS}}\right)$ and gate voltage $\left(\mathrm{V}_{\mathrm{GS}}\right)$ and (b) transfer characteristics at $\mathrm{V}_{\mathrm{DS}}=5 \mathrm{~V}, 4 \mathrm{~V}, 3 \mathrm{~V}$, and $2 \mathrm{~V}$ for a functional CNTFET, respectively; the IDS on/off ratio is 490 .

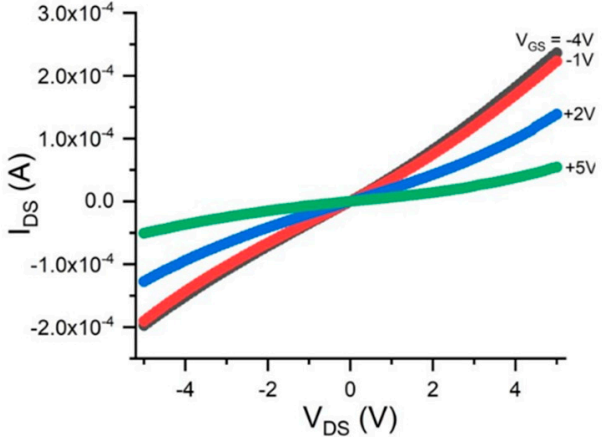

(a)

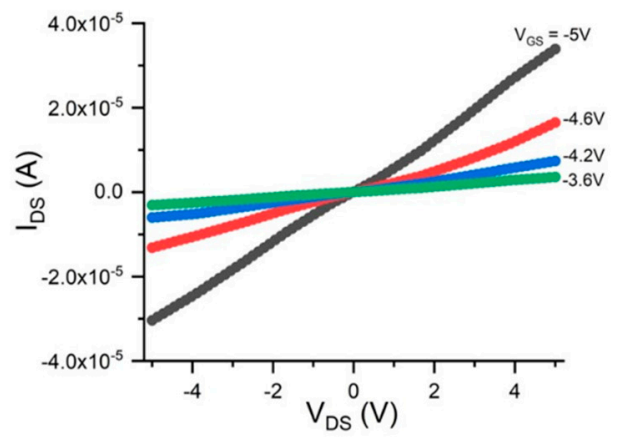

(c)

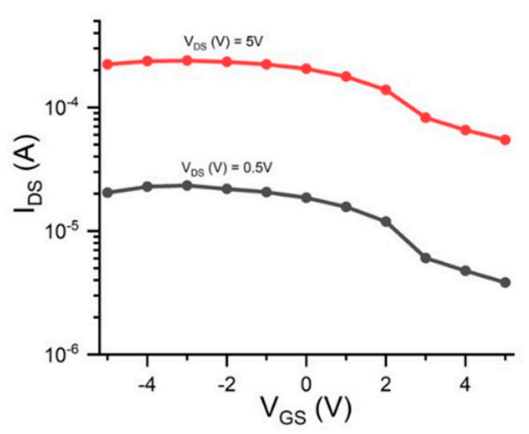

(b)

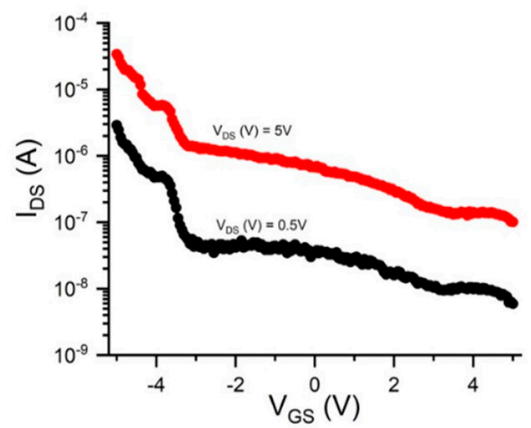

(d)

Figure 8. (a) Drain-source current $\left(\mathrm{I}_{\mathrm{DS}}\right)$ versus drain-source voltage $\left(\mathrm{V}_{\mathrm{DS}}\right)$ and gate voltage $\left(\mathrm{V}_{\mathrm{GS}}\right)$ and (b) transfer characteristics at $\mathrm{V}_{\mathrm{DS}}=5 \mathrm{~V}$ and $0.5 \mathrm{~V}$ for a functional CNTFET, respectively, where the $\mathrm{I}_{\mathrm{DS}}$ on/off ratio is 4 at $\mathrm{V}_{\mathrm{DS}}=5 \mathrm{~V}$ and 6 at $\mathrm{V}_{\mathrm{DS}}=0.5 \mathrm{~V} ;(\mathbf{c}, \mathbf{d})$ Similar curves as in $(\mathbf{a}, \mathbf{b})$ but measured after the CNTFET was subjected to the electrical breakdown process, where the $\mathrm{I}_{\mathrm{DS}}$ on/off ratio is 339 at $\mathrm{V}_{\mathrm{DS}}=5 \mathrm{~V}$ and 488 at $\mathrm{V}_{\mathrm{DS}}=0.5 \mathrm{~V}$.

\section{Summary}

We present the wafer-scale fabrication of carbon nanotube field-effect transistors (CNTFETs) with carbon nanotubes as the active channel material by using the dielectrophoresis (DEP) process. A device wafer with 30 CNTFETs was fabricated and characterized successfully, and it was found that $87 \%$ of the fabricated CNTFETs was functional and that, among the functional CNTFETs, $30 \%$ of the CNTFETs had an IDS on/off ratio larger than 20 while $70 \%$ of the CNTFETs had an $I_{D S}$ on/off ratio under 20 . The highest $I_{D S}$ on/off 
ratio was 490 . The variation of $\mathrm{I}_{\mathrm{DS}}$ on/off ratios in the CNTFETs is mainly due to the effect of the metallic carbon nanotubes in the channel. If the source carbon nanotubes are pure semiconducting tubes or have fewer metallic tubes, the $\mathrm{I}_{\mathrm{DS}}$ on/off ratios should be much higher and the variation of the ratios should be much smaller. The electrical breakdown was used to improve the $\mathrm{I}_{\mathrm{D}}$ on/off ratios of the CNTFET, and it was found that it significantly increased the $\mathrm{I}_{\mathrm{DS}}$ on/off ratios of the fabricated CNTFET. The DEP-based positioning of carbon nanotubes (CNTs) in the fabrication of CNTFETs is simple and effective. The DEP-based method can be easily extended for the assembly of other nanomaterials in the development of the wafer-scale fabrication of devices. The DEP-based device fabrication steps are compatible with Si technology processes, can be further optimized following process development protocols practiced by the semiconductor industry, and can lead to the wafer-scale fabrication of CNT electronic devices and sensors.

Author Contributions: Z.X. designed the experiments, fabricated the materials and devices, measured the electrical properties of the devices, analyzed the data, and wrote the manuscript. J.K. performed the fabrication and characterization of the devices. L.W. performed the fabrication and characterization of the devices. Q.Y. performed the experiment in the preparation of the CNT solution and the dielectrophoresis process and contributed to writing the manuscript. All authors have read and agreed to the published version of the manuscript.

Funding: This research was supported by U.S. Department of Energy, Office of Basic Energy Sciences, under Contract No. DE-SC00112704; National Science Foundation under Grant No. CBET-1740687; and Department of Defense under Grant No. W911NF-16-1-0554 and W911NF-17-1-0474.

Institutional Review Board Statement: Not applicable.

Informed Consent Statement: Not applicable.

Data Availability Statement: The data presented in this study are available on request from the corresponding author.

Acknowledgments: Research carried out in part at the Center for Functional Nanomaterials, Brookhaven National Laboratory, which is supported by the U.S. Department of Energy, Office of Basic Energy Sciences, under Contract No. DE-SC00112704; the research is supported by National Science Foundation under Grant No. CBET-1740687 and Department of Defense under Grant No. W911NF-16-1-0554 and W911NF-17-1-0474.

Conflicts of Interest: The authors declared no conflicts of interest.

\section{References}

1. Lemieux, M.C.; Roberts, M.; Barman, S.; Jin, Y.W.; Kim, J.M.; Bao, Z. Self-Sorted, Aligned Nanotube Networks for Thin-Film Transistors. Science 2008, 321, 101-104. [CrossRef]

2. Javey, A.; Guo, J.; Farmer, D.B.; Wang, Q.; Wang, D.; Gordon, R.G.; Lundstrom, A.M.; Dai, H. Carbon Nanotube Field-Effect Transistors with Integrated Ohmic Contacts and High-k Gate Dielectrics. Nano Lett. 2004, 4, 447-450. [CrossRef]

3. Seidel, R.V.; Graham, A.P.; Kretz, J.; Rajasekharan, B.; Duesberg, G.S.; Liebau, M.; Unger, E.; Kreupl, F.; Hoenlein, W. Sub-20 nm Short Channel Carbon Nanotube Transistors. Nano Lett. 2005, 5, 147-150. [CrossRef]

4. Wang, H.; Cobb, B.; Van Breemen, A.; Gelinck, G.G.; Bao, Z. Highly Stable Carbon Nanotube Top-Gate Transistors with Tunable Threshold Voltage. Adv. Mater. 2014, 26, 4588-4593. [CrossRef]

5. Qiu, C.; Zhang, Z.; Zhong, D.; Si, J.; Yang, Y.; Peng, L.-M. Carbon Nanotube Feedback-Gate Field-Effect Transistor: Suppressing Current Leakage and Increasing On/Off Ratio. ACS Nano 2015, 9, 969-977. [CrossRef] [PubMed]

6. Wanga, H.; Weib, P.; Lic, Y.; Hanb, J.; Leec, H.; Naabd, B.; Liub, N.; Wange, C.; Adijantob, E.; Teec, B.; et al. Tuning the threshold voltage of carbon nanotube transistors by n-type molecular doping for robust and flexible complementary circuits. Proc. Natl. Acad. Sci. USA 2014, 111, 4776. [CrossRef] [PubMed]

7. Sun, D.-M.; Timmermans, M.Y.; Tian, Y.; Nasibulin, A.G.; Kauppinen, E.I.; Kishimoto, S.; Mizutani, T.; Ohno, Y. Flexible high-performance carbon nanotube integrated circuits. Nat. Nanotechnol. 2011, 6, 156-161. [CrossRef] [PubMed]

8. Ding, L.; Zhang, Z.; Liang, S.; Pei, T.; Wang, S.; Li, Y.; Zhou, W.; Liu, J.; Peng, L.-M. CMOS-based carbon nanotube pass-transistor logic integrated circuits. Nat. Commun. 2012, 3, 677. [CrossRef]

9. Kim, B.; Jang, S.; Geier, M.L.; Prabhumirashi, P.L.; Hersam, M.C.; Dodabalapur, A. High-Speed, Inkjet-Printed Carbon Nanotube/Zinc Tin Oxide Hybrid Complementary Ring Oscillators. Nano Lett. 2014, 14, 3683-3687. [CrossRef]

10. Zaumseil, J. Single-walled carbon nanotube networks for flexible and printed electronics. Semicond. Sci. Technol. 2015, 30. [CrossRef] 
11. Chen, H.; Cao, Y.; Zhang, J.; Zhou, C. Large-scale complementary macroelectronics using hybrid integration of carbon nanotubes and IGZO thin-film transistors. Nat. Commun. 2014, 5, 4097. [CrossRef] [PubMed]

12. Park, S.; Vosguerichian, M.; Bao, Z. A review of fabrication and applications of carbon nanotube film-based flexible electronics. Nanoscale 2013, 5, 1727. [CrossRef] [PubMed]

13. Zhang, Z.; Liang, X.; Wang, S.; Yao, K.; Hu, Y.; Zhu, Y.; Chen, Q.; Zhou, W.; Li, Y.; Yao, Y.; et al. Doping-Free Fabrication of Carbon Nanotube Based Ballistic CMOS Devices and Circuits. Nano Lett. 2007, 7, 3603-3607. [CrossRef]

14. Geier, M.L.; Prabhumirashi, P.L.; McMorrow, J.J.; Xu, W.; Seo, J.-W.T.; Everaerts, K.; Kim, C.H.; Marks, T.J.; Hersam, M.C. Subnanowatt Carbon Nanotube Complementary Logic Enabled by Threshold Voltage Control. Nano Lett. 2013, 13, $4810-4814$. [CrossRef]

15. Chen, Z.; Appenzeller, J.; Lin, Y.-M.; Sippel-Oakley, J.; Rinzler, A.G.; Tang, J.; Wind, S.J.; Solomon, P.M.; Avouris, P. An Integrated Logic Circuit Assembled on a Single Carbon Nanotube. Science 2006, 311, 1735. [CrossRef]

16. Wei, B.Q.; Vajtai, R.; Ajayan, P.M. Reliability and current carrying capacity of carbon nanotubes. Appl. Phys. Lett. 2001, 79, 1172-1174. [CrossRef]

17. White, C.T.; Todorov, T.N. Quantum electronics: Nanotubes go ballistic. Nature 2001, 411, 649. [CrossRef]

18. Datta, S. Electronic Transport Properties in Mesoscopic Systems; Cambridge University Press: Cambridge, UK, 1995.

19. Shulaker, M.M.; Hills, G.; Patil, N.; Wei, H.; Chen, H.-Y.; Wong, H.-S.P.; Mitra, S. Carbon nanotube computer. Nat. Cell Biol. 2013, 501, 526-530. [CrossRef]

20. Xiao, Z.; Elike, J.; Reynolds, A.; Moten, R.; Zhao, X. The fabrication of carbon nanotube electronic circuits with dielectrophoresis. Microelectron. Eng. 2016, 164, 123-127. [CrossRef]

21. Jariwala, D.; Sangwan, V.K.; Lauhon, L.J.; Marks, T.J.; Hersam, M.C. Carbon nanomaterials for electronics, optoelectronics, photovoltaics, and sensing. Chem. Soc. Rev. 2013, 42, 2824-2860. [CrossRef]

22. Peng, L.-M.; Zhang, Z.; Wang, S. Carbon nanotube electronics: Recent advances. Mater. Today 2014, 17, 433-442. [CrossRef]

23. Shulaker, M.M.; Van Rethy, J.; Wu, T.F.; Liyanage, L.S.; Wei, H.; Li, Z.; Pop, E.; Gielen, G.; Wong, H.-S.P.; Mitra, S. Carbon Nanotube Circuit Integration up to Sub-20 nm Channel Lengths. ACS Nano 2014, 8, 3434-3443. [CrossRef] [PubMed]

24. Benedict, L.X.; Louie, S.G.; Cohen, M.L. Static polarizabilities of single-wall carbon nanotubes. Phys. Rev. B 1995, 52, 8541-8549. [CrossRef] [PubMed]

25. Zhang, Z.-B.; Liu, X.; Campbell, E.E.B.; Zhang, S.-L. Alternating current dielectrophoresis of carbon nanotubes. J. Appl. Phys. 2005, 98, 56103. [CrossRef]

26. Li, P.; Xue, W. Selective Deposition and Alignment of Single-Walled Carbon Nanotubes Assisted by Dielectrophoresis: From Thin Films to Individual Nanotubes. Nanoscale Res. Lett. 2010, 5, 1072-1078. [CrossRef] [PubMed]

27. Yang, B.; Yang, Z.; Zhao, Z.; Hu, Y.; Li, J. The assembly of carbon nanotubes by dielectrophoresis: Insights into the dielectrophoretic nanotube-nanotube interactions. Phys. E Low-Dimens. Syst. Nanostruct. 2014, 56, 117-122. [CrossRef]

28. Naieni, A.K.; Nojeh, A. Effect of solution conductivity and electrode shape on the deposition of carbon nanotubes from solution using dielectrophoresis. Nanotechnology 2012, 23, 495606. [CrossRef]

29. Xiao, Z.; Sharma, H.; Zhu, M.Y.; Pearson, T. Dielectrophoresis-assisted deposition and alignment of single-walled carbon nanotubes for electronic-device fabrication. J. Vac. Sci. Technol. A 2010, 28, 750-754. [CrossRef]

30. Krisnadi, F.; Nguyen, L.L.; Ankit; Ma, J.; Kulkarni, M.R.; Mathews, N.; Dickey, M.D. Directed Assembly of Liquid Metal-Elastomer Conductors for Stretchable and Self-Healing Electronics. Adv. Mater. 2020, 32, 2001642. [CrossRef]

31. Naieni, A.K.; Nojeh, A. Dielectrophoretic deposition of carbon nanotubes: The role of field frequency and its dependence on solution conductivity. Microelectron. Eng. 2014, 114, 26-30. [CrossRef]

32. Shekhar, S.; Stokes, P.; Khondaker, S.I. Ultrahigh Density Alignment of Carbon Nanotube Arrays by Dielectrophoresis. ACS Nano 2011, 5, 1739-1746. [CrossRef] [PubMed]

33. Sarker, B.K.; Shekhar, S.; Khondaker, S.I. Semiconducting Enriched Carbon Nanotube Aligned Arrays of Tunable Density and Their Electrical Transport Properties. ACS Nano 2011, 5, 6297-6305. [CrossRef] [PubMed]

34. Tittmann-Otto, J.; Hermann, S.; Kalbacova, J.; Hartmann, M.; Toader, M.; Rodriguez, R.D.; Schulz, S.; Zahn, D.R.T.; Gessner, T. Effect of cleaning procedures on the electrical properties of carbon nanotube transistors-A statistical study. J. Appl. Phys. 2016, 119, 124509. [CrossRef]

35. Liu, B.; Liu, J.; Li, H.-B.; Bhola, R.; Jackson, E.A.; Scott, L.T.; Page, A.J.; Irle, S.; Morokuma, K.; Zhou, C. Nearly Exclusive Growth of Small Diameter Semiconducting Single-Wall Carbon Nanotubes from Organic Chemistry Synthetic End-Cap Molecules. Nano Lett. 2015, 15, 586. [CrossRef]

36. Xiao, Z.; Williams, L.; Kisslinger, K.; Sadowski, J.T.; Camino, F. Fabrication of field-effect transistors with transfer-free nanostructured carbon as semiconducting channel material. Nanotechnology 2020, 31, 485203. [CrossRef]

37. Xiao, Z.; Kisslinger, K.; Chance, S.; Banks, S. Comparison of Hafnium Dioxide and Zirconium Dioxide Grown by Plasma-Enhanced Atomic Layer Deposition for the Application of Electronic Materials. Crystals 2020, 10, 136. [CrossRef]

38. Collins, P.G.; Arnold, M.S.; Avouris, P. Engineering Carbon Nanotubes and Nanotube Circuits Using Electrical Breakdown. Science 2001, 292, 706-709. [CrossRef]

39. Otsuka, K.; Inoue, T.; Chiashi, S.; Maruyama, S. Selective removal of metallic single-walled carbon nanotubes in full length by organic film-assisted electrical breakdown. Nanoscale 2014, 6, 8831-8835. [CrossRef] 
40. Xiao, Z; Camino, F.E. The fabrication of carbon nanotube field-effect transistors with semiconductors as the source and drain contact materials. Nanotechnol. 2009, 20, 135205. [CrossRef]

41. Xiao, Z.; Camino, F.E. An Effective Switching-Off Mechanism for High-Performance Carbon Nanotube Field-Effect Transistors. J. Nanoelectron. Optoelectron. 2010, 5, 26-29. [CrossRef]

42. Avouris, P. Carbon nanotube electronics. Chem. Phys. 2002, 281, 429. [CrossRef]

43. Avouris, P.; Martel, R.; DeRycke, V.; Appenzeller, J. Carbon nanotube transistors and logic circuits. Phys. B Condens. Matter 2002, 323, 6-14. [CrossRef]

44. Martel, R.; DeRycke, V.; Appenzeller, J.; Wind, S.; Avouris, P. Carbon nanotube field-effect transistors and logic circuits. In Proceedings of the ACM/IEEE Design Automation Conference, New Orleans, LA, USA, 10-14 June 2002; pp. 94-98.

45. Xiao, Z.; Kisslinger, K. Electron-beam-evaporated thin films of hafnium dioxide for fabricating electronic devices. J. Vac. Sci. Technol. B 2015, 33, 042001. [CrossRef]

46. Schroter, M.; Claus, M.; Sakalas, P.; Haferlach, M.; Wang, D. Carbon Nanotube FET Technology for Radio-Frequency Electronics: State-of-the-Art Overview. IEEE J. Electron Devices Soc. 2013, 1, 9-20. [CrossRef]

47. Franklin, A.D.; Koswatta, S.O.; Farmer, D.B.; Smith, J.T.; Gignac, L.; Breslin, C.M.; Han, S.-J.; Tulevski, G.S.; Miyazoe, H.; Haensch, W.; et al. Carbon Nanotube Complementary Wrap-Gate Transistors. Nano Lett. 2013, 13, 2490-2495. [CrossRef] 